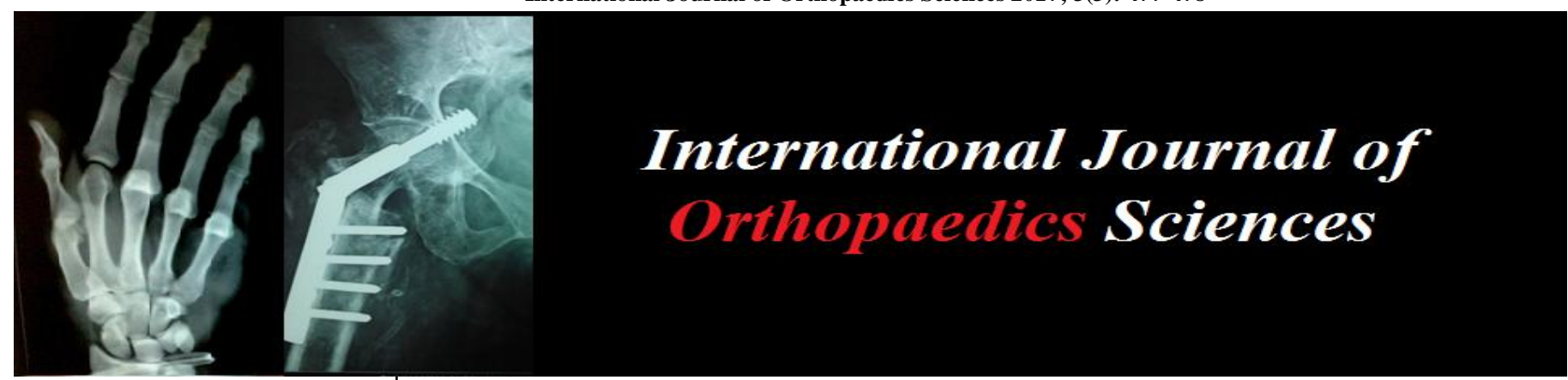

ISSN: 2395-1958

IJOS 2017; 3(3): 477-478

(C) 2017 IJOS

www.orthopaper.com

Received: 10-05-2017

Accepted: 11-06-2017

Prof. Dr. S Veera Kumar Professor, Department of Orthopedics, Government Stanley Medical College, Royapuram, Chennai, Tamil Nadu, India

Dr. Kathir Azhagan S Resident Department of Orthopedics, Government Stanley Medical College, Royapuram, Chennai, Tamil Nadu, India
Correspondence

Dr. Kathir Azhagan S

Professor, Department of Orthopedics, Government Stanley Medical College, Royapuram, Chennai, Tamil Nadu, India

\section{Osteochondroma of talus}

\section{Prof. Dr. S Veera Kumar and Dr. Kathir Azhagan S}

DOI: http://dx.doi.org/10.22271/ortho.2017.v3.i3g.80

\section{Abstract}

Osteochondroma or exostosis is the most common benign bone tumor, and occurring frequently around knee and proximal humerus. It rarely affects pelvis, vertebra, spine. Osteochondroma of talus is a very rare ${ }^{[1]}$. We report a rare case of extensive osteochondroma of the talus in a 50 year old male presenting with swelling around the ankle and symptoms suggestive of tarsal tunnel syndrome. En-block excision of the multiple masses was done. Histopathological examination confirmed the diagnosis of osteochondroma. Although most of the osteochondromas are being treated conservatively, those presenting with pain, multiple swellings, restriction of movements should be treated with surgical excision. Careful Excision is a successful method of treatment for symptomatic osteochondromas with low recurrence.

Keywords: Exostosis, Osteochondroma, Talus

\section{Introduction}

Osteochondroma is a most common primary benign bone tumor commonly seen in children or young adult. It is accepted well beyond proof that it arises from metaphyseal region of bones originating from enchondral ossification like long tubular bones of limbs and less commonly in short tubular bones of hand and foot. Flat bone Osteochondroma occurrence in pelvis, vertebra, scapula is being reported across the globe. We are reporting a rare case of extensive talus Osteochondroma in a skeletally mature male patient of age 60 years.

\section{Case report}

50 year male presented with a painful mass on a lateral aspect of right foot. pain was insidious in onset, dull aching, localized, aggravated by activitity and relieves with rest. Swelling was initially little like a bean aand progressed gradually to present size of a lemon, patient report occasional edema with increased activity.

On examination, there was a irregular bony hard swelling just below lateral malleolus. range of movement was restricted especially eversion of ankle joint. distal vascularity felt normal and there was neither motor nor sensory neurological deficit.

On investigation, general laboratory investigation were normal. radiograph showed a bony outgrowth of $4 \mathrm{X} 4 \mathrm{X} 3 \mathrm{~cm}$ arising from the lateral process of right talus was located. CT confirms the location and thrown a light on medullary continuity, measuring the cartilage cap size and to rule out malignancy radiologically.

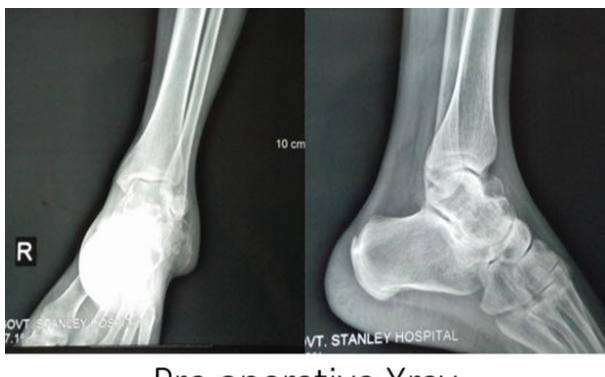

Pre operative Xray

The mass was surgically removed through lateral approach. Intraoperatively the cartilage surface of the mass was found to be irregular. 


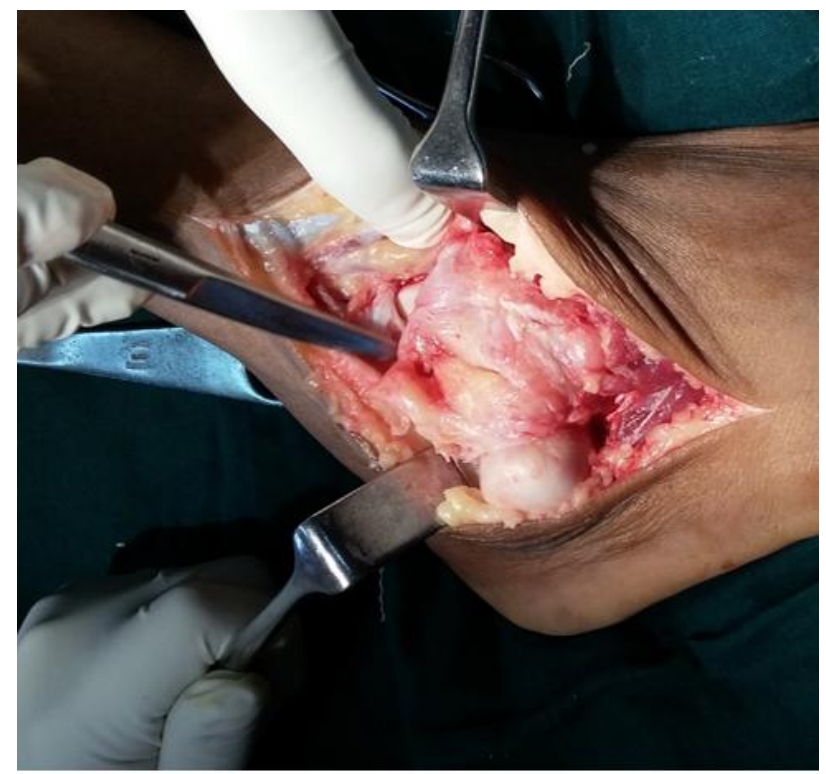

Intraoperative

Extra periosteal excision of tumor done and sent for histopathological confirmation. Histo Pathology examination revealed hyaline cartilage cap and underlying bony spicules with regularly arranged column of cartilage cells and embedded cartilage island within underlying bone

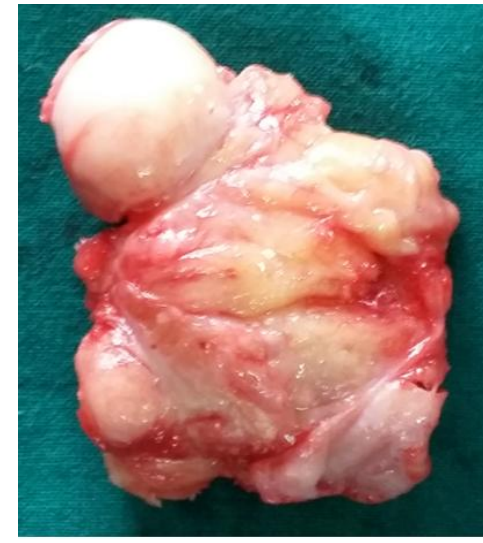

Gross specimen

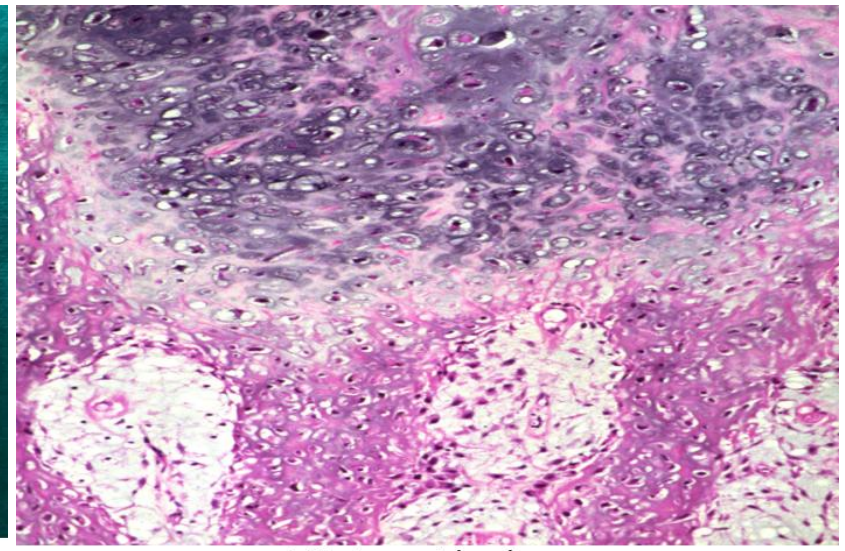

Histopathology
1 year later the patient was asymptomatic without any signs of recurrence.

\section{Discussion}

Osteochondroma of the talus is rare but must be considered as part of the differential diagnosis of any swelling in this part of the skeleton. Osteochondroma of talus was reported in 1984 by Fuselier CO et al ${ }^{[2]}$. Chioros et al in 1987 reported an atypical osteochondroma from the posterior aspect of talus in a 34 year old male ${ }^{[3]}$. Again in 2003 Ebler et al reported an osteochondroma arising from the dorsum of talus ${ }^{[4]}$. But in our case, the location was lateral process of Talus and occurred in the sixth decade, which is contrary to the existing reports in the literature.

Its must be noted that Differential diagnosis of a bony swelling at this location which clinically and radiologically appears benign arising from an atypical location in an elderly patient includes heterotrophic ossification, florid reactive periostitis, Nora's lesion, turret exostoses and Osteochondroma. Osteochondroma of talus may also present as a loose body in the ankle joint. Patients who primarily complain of pain should be informed that there is an increased risk of pain related to surgery or its complications. Considering that $11.6 \%$ of the patients were not fully satisfied with the surgery and that $4.7 \%$ would not have surgery again, we see no justification for the prophylactic excision of asymptomatic osteochondromas. Surgical indications are pain, disturbance of growth, decreased range of movement, bursitis, peduncle fractures and symptoms secondary to compression of peripheral neuro vascular structures. Major complications and local recurrence are rare

\section{Reference}

1. Osteochondroma of the talus Joint Diseases and Related Surgery Eklem Hastalık Cerrahisi, 2010; 21(2):116-117.

2. Şahap Atik O, Baran Sarıkaya MD, Cemalettin MD, Kunat MD, Ramin Muradi MD, Bahadır Ocaktan MD et al. Solitary osteochondroma of the foot: an in-depth study with case reports. J Foot Surg. 1984; 23(1):3-24.

3. Fuselier CO, Binning T, Kushner D, Kirchwehm WW, Rice JR, Hetherington Vet al. Unusual osteochondroma of the foot and ankle J Foot Surg. 1987; 26(5):407-11.

4. Chioros PG, Frankel SL, Sidlow CJ. Osteochondroma talus: a case report J of Evolution of Med and Dent Sci/ eISSN- 2278-4802, pISSN- 2278-4748. 2015; 4(03)08. Ch. V Murali Krishna1, P. Ashok Kumar2, P. Rambabu3, K. Srinivasa Rao4, M. Sathish5 